\title{
ЖАНРОВЫЙ СИНКРЕТИЗМ СОВРЕМЕННОГО РОМАНА (НА МАТЕРИАЛЕ РОМАНА «ЗУЛЕЙХА ОТКРЫВАЕТ ГЛАЗА» ГУЗЕЛЬ ЯХИНОЙ)
}

Жанровый синкретизм как изменение иерархической системы отношений является типологической особенностью всех видов и жанров искусства. В современной литературе жанровый синкретизм проявился в преодолении жанрового канона и использовании многомодальности в рамках одного произведения. Причину смешения жанров следует видеть, с одной стороны, в многозначности реальности, которая «сопротивляется» стремлению воплотить её в одномерную жанровую структуру. С другой, этот процесс вызван «текучестью жанра», «поливариантностью» внутри системы жанровых координат (Khalizev 13), в результате чего (Khalizev 13) возникают синтетические жанры.

Процесс жанрового синкретизма является устойчивой тенденцией, характерной для многих литературных форм. Трансформация в структуре жанра на примере романа, который за три тысячелетия приобрёл разветвлённую жанровую систему, определившую «типические аспекты выражения смысла» (Teoriya literaturnykh 5), даёт возможность наблюдать линии изменения жанровых моделей. Существует мнение, что именно с романной формы началось разрушение концепции жанров (Teoriya literaturnykh 4), и образование неканонических и образование неканоническиструктур романа.

Nadezhda Andreyevna Levitskaya (НАдЕжда АндРеввна Левитская) - кандидат педагогических наук, Московский государственный областной педагогический университет; адрес для почтовых отправлений: ул. Фридриха Энгельса, д. 4, 105005 Москва; e-mail: nlevitskaia @mail.ru; ORCID: https://orcid.org/0000-0001-5708-0433.

NADEZHDA ANDREYEVNa LevitSKAYA - kandydat nauk pedagogicznych, Moskiewski Państwowy Regionalny Uniwersytet Pedagogiczny; adres do korespondencji: ул. Фридриха Энгельса, д. 4, 105005 Москва; е-mail: nlevitskaia@mail.ru; ORCID: https://orcid.org/0000-00015708-0433. 
За счёт расширения объёма «памяти жанра» в современном романе совершился переход от дифференциации жанровых признаков к многомодальности. Поскольку «жанр - это содержательная форма» (Gachev 13), то жанровая принадлежность порождает типологические разновидности романов. В результате контаминации жанровых форм возникла новая многомерная художественная реальность, поскольку в процессе создания художественного целого происходит своеобразное «единоборство новой творческой идеи и преднаходимой жанровой структуры» (Gachev 20).

Примерами жанровой многомодальности (неканонической структуры романа) могут служить многие произведения новейшей литературы: сплавом исторической хроники, романа-жизнеописания, плутовского романа и триллера является роман Обитель 3. Прилепина (2014). Роман о Соловецком лагере основан на реконструкции воспоминаний прадеда писателя, свидетеля и участника Секирского восстания заключённых.

Несколько жанровых формул использует Е. Водолазкин в философском романе Брисбен (2019), жанровым ядром которого является кюнстлерроман (жизнеописание художника). Написанный в форме романабиографии, Брисбен хранит глубокую жанровую память, связывающую его с традицией древнерусской литературы (агиографической литературой). Жизнь главного героя, музыканта мирового уровня Глеба Яновского, страдающего неизлечимой болезнью, превращается в житие с восхождением на Голгофу ради воплощения лика Божия. Творческая тематика, высокая степень репрезентативности «вненаходимого» автора-творца, превращённого в текстового двойника, дают основание считать «Брисбен» современным метароманом.

Роман Текст Д. Глуховского (2016) может служить примером слияния нескольких жанровых формул. Жанровый канон социально-психологического романа претерпевает трансформацию: в него встраивается убийство и двойное расследование - и сюжет начинает развиваться по законам детективного жанра. Одновременно Текст - это роман-биография, так как в центре авторского внимания история жизни двух молодых людей, наших современников. В рецепции одного из них, бывшего заключённого, показана жизнь столицы и её ближайшего пригорода, что определило близость повествования к жанру нуар-романа («чёрного романа»).

В романе В. Пелевина, писателя-постмодерниста, Искусство лёгких касаний (2019) произошло сращение нескольких жанровых модально- 
стей: научно-фантастического романа, поп-арта, философского романа, травелога и апокрифической апокалиптической литературы, содержащей демонологический дискурс.

Примером произведений, в которых за счёт расширения объёма «памяти жанра» совершился переход от дифференциации жанровых признаков к многомодальности, могут служить и произведения Г. Яхиной: роман Зулейха открывает глаза (2014) и роман Дети мои, ставший литературным событием 2018 года.

Остановимся на романе Зулейха открывает глаза. Вектором жанрового синкретизма, обусловившего целостность произведения, является модель исторического романа. В романе о Зулейхе временные границы описываемых событий охватывают драматический период истории с 1930 по 1946 год. Это время массовых репрессий, связанных с коллективизацией, борьбой с инакомыслием и расправой с «социально чуждыми элементами». Война (41-45 гг.), хотя и не получает развёрнутого описания, но её разрушительность сказывается на судьбах спецпереселенцев посёлка Семрук.

Источником для создания романа послужили биографические факты, это история «из прошлого» («Guzel’ Yakhina o svoyey knige»), связанного с судьбой семьи самого автора. По словам Г. Яхиной, бабушка семилетней девочкой была в числе раскулаченных выслана в Сибирь, и её детские воспоминания послужили основой для жизни главной героини Зулейхи. Черты другой героини - властной Упырихи - были позаимствованы у прабабки («Guzel’ Yakhina o svoyey knige»). Автобиографическая основа романа, сопричастность автора всему происходящему во многом определила достоверность в изображении картин прошлого. Реконструкция исторических событий, отстоящих от момента написания книги почти на сто лет, потребовала от автора пересмотра оценки не только исторических явлений, но и поиска новых литературных форм.

Этот исторический период показан как время укрепления государственности, когда провозглашённые гуманистические принцип на деле обернулись созданием тоталитарной системы, основанной на диктате власти, подавлении личной свободы и рабском труде отдельных социальных групп. Не случайно писательница показывает жизнь спецпереселенцев, высланных в Сибирь, которые как враждебные народу элементы относились к категории репрессированных. Историческим ядром романа является процесс самопостижения народом своей самобытности в условиях дегуманизации государственных основ. 
Это даёт основание для построения историософской концепции романа, которая может быть рассмотрена через бинарную оппозицию: исторические преобразования в форме революционных катаклизмов уникальность и самоценность человеческой жизни.

В романе историческое время, приобретая циклический характер, становится ключом к пониманию бытия человека в быстро меняющемся мире. Диалог с прошлым в свете настоящего, острота поставленных вопросов о соотношении частной жизни и государственных интересов придают повествованию художественный политический дискурс (Glotova 158$)$.

По отбору и ракурсу изображаемых событий Зулейха открывает глаза является социально-психологическим романом. Герои романа представляют разные социальные слои: это крестьяне, оторванные от родной земли и привычного быта, представители русской интеллигенции, подлежащие в соответствии с проводимой политикой депортации в Сибирь, и стоявшие у руля коммунисты, чьими руками совершались подвиги и преступления, «до основания» разрушался старый мир и создавался новый.

Жизни главных героев соединены единой исторической судьбой. Переплетение и неразделимость судеб спецпереселенцев и их надзирателей в суровых условиях сибирской ссылки составляют сюжетную основу романа. Центральной темой романа является тема «маленького человека» на фоне государственных мифов о всеобщем равенстве, свободе, братстве.

Зулейха - крестьянка родом из татарской деревни Юлбаш, через судьбу которой показано перерождение патриархального мифологизированного сознания; коммунист Иван Игнатов, которому предстоит преодолеть догматизм революционного сознания; и профессор доктор Вольф Карлович Лейбе, сумевший победить обособленность индивидуалистического сознания (Yakhina 56).

История жизни Зулейхи - это роман-биография. В образе Зулейхи проступают архетипические свойства «простой души». В этой крестьянской женщине сохранилось много детскости, поведенческой странности, которая воспринимается как проявление забитости, почти юродства.

Три этапа её жизни становятся ступенями к открытию мира и уяснению своей роли в этом мире. Вначале она жертва бесчеловечных и уродливых семейных отношений: Зулейха почти не отличает день от ночи - так много приходится ей работать; добро от зла - так мало она 
видела добра. Весь патриархальный уклад жизни татарского села тяжким бременем лёг на хрупкие плечи женщины, в 15 лет выданной замуж за угрюмого, неласкового Муртазу, мужчину намного старше её.

После убийства продотрядовцами мужа из жертвы родовых отношений и собственности Муртазы она становится заложницей железного закона государственной машины. Как жена кулака Зулейха подлежит высылке в Сибирь. Отправляясь в Сибирь в общем вагоне, почти без пищи, Зулейха, подвергаясь унижениям, по-прежнему вынуждена терпеть, молчать и подчиняться.

Прозрение произойдёт на границе между жизнью и смертью. И Зулейха откроет глаза и увидит мир, в котором главной спасительной силой будут Добро, Любовь, Милосердие, Труд и Прощение. В плавильном котле общенародных исторических бед и страданий произойдёт преображение героини. Глядя на огромную географическую карту страны, она осознает себя её частью, малой её песчинкой. Вот тогда Зулейха «откроет глаза», поднимется с колен и станет равновеликой судьбе своего народа.

Обширное аллюзивное поле романа включает признаки и робинзонады (выживание людей в суровых условиях Сибири), и производственного романа, созданного в русле традиций социалистического реализма. Условием выживания спецпереселенцев, оказавшихся поздней осенью на берегу Ангары без одежды, пищи, необходимых инструментов, был труд. Как в любом производственном романе, автор описывает трудовые процессы, в которых принимают участие все уцелевшие жители выросшего на берегу Ангары посёлка Семрук. В результате коллективного труда вначале во имя выживания, а потом во имя общественного блага возникает ни с чем не сравнимая сила единения между людьми, зарождаются новые отношения, связывающие героев. Этот новый тип взаимоотношений, построенный на служении ближнему, проявится и в том, как доктор Лейбе будет беззаветно спасать от гибели всех больных и страждущих, и в том, как Зулейха самоотверженно будет ему помогать, выполняя тяжёлую работу. Принципы альтруистической этики, основанные на личной ответственности, станут эталоном поведения, основой исторической общности, именуемой народом.

Немалое место в романе занимает образ коммуниста Ивана Игнатова, героя, хорошо узнаваемого по образцам советской литературы, он из тех, у кого «пожаром восстаний» горели «гордые души» (В.Т. Кириллов). Традиционный образ коммуниста, стоящего во главе историче- 
ского преображения государства, получает новое художественное решение. Иван Игнатов готов жертвовать собой ради революции, но он не свободен от ошибок и заблуждений. Его прозрение начнётся с осознания бесчеловечности государственной системы. На протяжении романа из человека революционной воли, действующего именем революции, он превращается в рефлексирующего героя. Являясь частью карательного механизма государственной машины, он сам попадёт под её безжалостные удары. И тогда у него «откроются глаза» (устойчивая метафора романа), и он поймёт утопичность революционных идеалов. Ему предстоит пройти путь покаяния. Открытый финал даёт возможность додумать судьбу Игнатова. Станет ли для него спасительной любовь к Зулейхе, с которой так часто пересекалась его судьба, или ему суждено стать бойцом революции, перемолотым карательной государственной системой?

Преодоление канона жанровых структур проявилось в романе «в индивидуальной авторской инициативе» (Sovremennaya russkaya literatura $818)$, которая заключается в свободном использовании закреплённых за каждым жанром комплекса художественных средств. И это даёт возможность писателю расширить арсенал средств для воплощения замысла произведения.

Автор обращается к парадигме метода социалистического реализма и одновременно спорит с ней, противопоставляя идее казарменного социализма духовную жизнь репрессированной части народа. Тематически роман Г. Яхиной перекликается с произведениями о коллективизации и раскулачивании крестьянства (М. Шолохов Поднятая целина, Ф.И. Панфёров Бруски), с произведениями на лагерную тему (В. Шаламов, А. Солженицын, Л. Гинзбург).

Вихрь событий держит в необычайном напряжении читательское внимание и передаёт напряжённость и драматизм происходящего через ускорение времени и сверхбыструю смену действий. В этом сказалось несомненное влияние на литературу кинематографического жанра экшен. Это сцены «кражи» Зулейхой пастилы для духа кладбища «зират иясе», чтобы тот «присмотрел за могилами дочек» (Yakhina 25), аварии на барже «Клара», перевозившей переселенцев через Ангару, рождение Зулейхой сына Юзуфа на берегу реки, сцены с нападением волков на Юзуфа, охота на медведя и др.

Для перенесения событий романа в условную реальность автором используются элементы магического реализма. Использование приёмов 
магического реализма дали возможность автору проникнуть во внутренний мир героев. Общение Зулейхи со сверхъестественными существами, демонами выявляют устойчивые мифологемы индивидуального сознания. А параллельный мир, в котором оказывается потрясённый происходящими кровавыми событиями профессор Вольф Карлович Лейбе, отгородившийся от ужаса революционного переустройства мира, позволяет обнажить абсурдность нового жизнеустройства. Потрясённое сознание рождает фантом в виде «фантастического яйца», готового окончательно поглотить профессора. Алогизм его существования равновелик нелепости происходящего.

Писательница достоверно передаёт миг чужого бытия, поэтому подлинным предстаёт экзистенциальный опыт героев. Для автора граница в мир героев проницаема, он выступает как равноправный субъект повествования, которое ведётся от третьего лица. Автор (экзегетический нарратор) (Shmidt 203) не принадлежит к миру героев и не встроен в сюжет, писательница создаёт картину жизни, не включая личностное «я» в событийный ряд, что создаёт некоторую дистанцию между повествующим и действующим. Вместе с тем, речь автора приближена к языку героев, и тон повествования близок к «интенции и слову героя». Граница между автором и героями почти неразличима: авторский голос сливается с голосом героя (поэтому так велика роль несобственно прямой речи).

Важнейшим средством создания объёмной картины жизни становится интермедиальность, т.е. приёмы, свойственные иным видам искусства. Эффект визуализации возникает у читателя во многом благодаря тому, что Яхина мастерски владеет приёмами литературной кинематографичности. В интервью писательница подчеркнула, что вначале был написан сценарий к фильму, и только позже текст романа.

Литературная кинематографичность реализуется в динамической ситуации наблюдения, динамической детализации и визуализации деталей (Pavlova 25). Это даёт возможность добиться точности в пластике воссоздания картин прошлого, и делает органичным вхождение читателя в художественное пространство романа.

Использование динамической ситуации наблюдения даёт автору возможность создавать движение оживающих под пером картин действительности. Яхина применяет приёмы визуализации деталей, которым придаёт динамику преображения, так называемую «динамическую детализацию» (Pavlova 25). Так в романе показана рубка леса: «сначала 
утаптывают снег вокруг. Потом Муртаза скидывает тулуп, указывает топором в просвет между деревьями (туда будем валить) - и начинает рубить. Лезвие поблескивает на солнце и входит в берёзовый бок с коротким гулким «чах». «Ах! Ах! - отзывается эхо. Топор стёсывает толстую, причудливо изрисованную чёрными буграми кору, затем вонзается в нежно-розовую древесную мякоть. Щепа брызжет, как слёзы. Эхо наполняет лес» (Yakhina 19).

Дополнительную семантику всему происходящему придаёт звукопись, которая вносит в полинасыщенный текст ещё одно измерение. Например, появление непрошеных гостей в доме Муртазы сопровождается звуковым многообразием, добавляющим полноту динамично развивающимся событиям: «в ворота застучали», «Так зло и неумолимо стучит усталый хозяин, вернувшийся домой и внезапно обнаруживший свой дом кем-то запертым изнутри», «засов на воротах бряцает», «двор наполняется голосами, ржанием лошадей», «хлопает дверь в сенях», «топот кованых сапог по мёрзлым доскам», «половицы скрипят громко и истошно», «лязг печной заслонки», «чирканье спички», «треск разгорающегося огня в печи» (Yakhina 78).

\section{ВЫВОД}

Роман Зулейха открывает глаза можно считать образцом неканонического романного жанра: в результате преодоления жанровых формул произошла трансформация, которая привела к жанровому синкретизму, основанному на сращении крупных повествовательных форм. С целью объективации повествования для выявления неизученных глубин человеческой жизни и интерпретации травматического опыта русской истории Г. Яхина в рамках одного произведения использует гибридизацию жанровых формул.

Это дало возможность писательнице решить художественную задачу по отражению многозначной реальности, не укладывающейся в рамки одномерного жанрового канона. Вектором жанрового синкретизма, обусловившего целостность произведения, стала модель исторического романа, в котором автор реконструирует бытование человека в исторически меняющемся мире. Объединение нескольких жанровых формул способствовало расширению арсенала средств, в частности, изменению типологии конфликтов, характерных для определённого жанра. 
В русле жанра исторического романа, не снимая драматизма противостояния личности и общества, личности и истории, Г. Яхина показала процесс постижения народом своей самобытности в условиях дегуманизации государственных основ.

В романе Зулейха открывает глаза сохраняется важный для жанра романа-биографии процесс становления личности, способной преодолеть репрессивный механизм власти. Используя принципы социально-психологического романа, автор показывает драматические противоречия между героями из разных социальных слоёв и государственной системой, что придало широту в освещении событий прошлого. Через жанровую связь с производственным романом показана преобразующая сила коллективного труда как важнейшей формы национальной общности. Труд в условиях выживания спецпереселенцев в далёкой Сибири на берегах Ангары помогает преодолеть не только узость индивидуального сознания («слепоту») героев, но становится основой самосознания народа.

Путь превращения отдельного человека в народ и слияние отдельной жизни с историческими судьбами страны показаны через мистерию перерождения главных героев романа. Мистическая формула романа (магический реализм) даёт возможность расширить границы изображаемого, чтобы показать внутренний мир героев.

Вместе взятое, дало возможность Яхиной создать роман, в котором оппозиция человек - общество приобретает многомерность благодаря использованию различных жанровых локальностей, что позволяет расширить границы изображаемого и выстроить многоуровневый конфликт.

В романе происходит усиление авторского начала. И хотя текст остаётся полем интерпретации читателя, но в нём заметно усиление авторской субъектности. Манифестация авторского Я реализуется в разнообразных авторских стратегиях нарратива, через использование интермедиальных приёмов и близость к «интенции делу и слову героя», что усиливает эффект присутствия, тем самым приближая историческое прошлое к сегодняшнему дню. Это даёт основание считать, что Зулейха открывает глаза Г. Яхиной - это новая модель романной формы, сохранившей связь с традицией русского реалистического романа. 


\section{БИБЛИОГРАФИЯ}

Breyninger, Ol'ga. «Ya voshla v roman. Kak v svoy dom». God literatury, godliteratury.ru/ articles/2018/05/14/breyninger-yakhina-volga. Dostup 20.02.2020. [Брейнингер, Ольга. «Я вошла в роман. Как в свой дом». Год литературы, godliteratury.ru/articles/ 2018/05/14/breyninger-yakhina-volga. Доступ 20.02.2020].

De Groot, Jerome. The Historical Novel. The new critical idiom. Routlendge, 2001.

Elsanek, Asiya. Osnovy literaturovedeniya. Analiz romannogo teksta. Flinta: Nauka, 2004 [Элсанек, Асия [Yanovna]. Основы литературоведения. Анализ романного текста. Флинта: Наука, 2004].

Gachev, G[eorgiy] D[mitriyevich]. Soderzhatel'nost' khudozhestvennykh form (Epos. Lirika. Teatr). Prosveshcheniye, 1968 [Гачев, Г[еоргий] Д[митриевич]. Содержательность художественных форм. (Эпос. Лирика. Театр). Просвещение, 1968.

Glotova, Ye.Yu. «Khudozhestvennyy politicheskiy diskurs i kriterii yegoopredeleniya». Izvestiya Rossiyskogo gosudarstvennogo pedagogicheskogo universiteta im. A. I. Gertsena, № 73, 2008, ss. 154-158 [Глотова, Е.Ю. «Художественный политический дискурс и критерии его определения». Известия Российского государственного педагогического университета им. А. И. Гериена, № 73, 2008, сc. 154-158].

«Guzel' Yakhina o svoyey knige „Zuleykha otkryvayet glaza”, babushke i stsenariyakh». Afisha Daily, daily.afisha.ru/brain/613-o-svoej-knige-zulejha-otkryvaet-glaza-babushke-i-scenariyah/. Dostup 20.02.2020. [«Гузель Яхина о своей книге „Зулейха открывает глаза”, бабушке и сценариях». Афиша Daily, daily.afisha.ru/brain/613-o-svoej-knige-zulejhaotkryvaet-glaza-babushke-i-scenariyah/. Доступ 20.02.2020].

Khalizev, Valentin. Teoriya literatury. Vysshaya shkola, 1999, www.rulit.me/books/teoriyaliteratury-read-6298-1.html. Dostup 20.02.2020. [Хализев, Валентин. Теория литеpamyры. Высшая школа, 1999, www.rulit.me/books/teoriya-literatury-read-6298-1.html. Доступ 20.02.2020]

Kostyukevich, Yelena. «Na vsyu glubinu». Guzel’ Yakhina. Deti moi. AST, 2018 [Костюкевич, Елена. «На всю глубину». Гузель Яхина. Дети мои. АСТ, 2018].

Leyderman, Naum. Teoriya zhanra. Issledovaniya i razbory. Ural'skiy gosudarstvennyy pedagogicheskiy universitet, 2010 [Лейдерман, Наум. Теория жанра. Исследования и разборы. Уральский государственный педагогический университет, 2010].

Paducheva, Yelena. Semanticheskiye issledovaniya: Semantika vremeni i vida v russkom yazyke. Semantika narrativa. Yazyki slavyanskoy kul'tury, 2010 [Падучева, Елена. Семантические исследования: Семантика времени и вида в русском языке. Семантика нарратива. Языки славянской культуры, 2010]

Pavlova, Nadezhda. «Poetika vizual'nosti v romane G. Yakhinoy „Deti moi”: k voprosu o fenomene literaturnogo uspekha». Kul'tura i tekst, no. 3 (34), 2018, ss. 52-66 [Павлова, Надежда. «Поэтика визуальности в романе Г. Яхиной „Дети мои”: к вопросу о феномене литературного успеха». Культура и текст, № 3 (34), 2018, сc. 52-66].

Savkina, Irina, i Rozenkhol'm Ar'ya. «,Sekret yeyë uspekha”: razmyshleniya o romane Guzel' Yakhinoy „Zuleykha otkryvayet glaza”». Labirint. Zhurnal sotsial'no-gumanitarnykh issledovaniy, no. 3-4, 2016, ss. 22-25 [Савкина, Ирина, и Розенхольм Арья. « „Секрет её успеха”: размышления о романе Гузель Яхиной „Зулейха открывает глаза”». Лабиринт. Журнал социально-гуманитарных исследований, № 3-4, 2016, сс. 22-25].

Shmidt, Vol'f. Narratologiya. Yazyki slavyanskoy kul'tury, 2003 [Шмидт, Вольф. Нарратология. Языки славянской культуры, 2003]. 
Sovremennaya russkaya literatura. 1900-ye gg. - nachalo XXI v., red. S. Timina, V. Vasil'yev, O. Voronina i dr., Akademiya, Filologicheskiy fakul'tet SPBGU, 2005 [Современная русская литература.1900-е гг. - начало XXI в., ред. С[ветлана Ивановна] Тимина, В[ладимир Ефимович] Васильев, О[льга Юрьевна] Воронина и др., Академия, Филологический факультет СПбГУ, 2005].

Teoriya literaturnykh zhanrov, red. N[atan] D[avidovich] Tamarchenko, Izdatel'skiy tsentr «Akademiуа», 2012 [Теория литературных жанров, ред. Н[атан] Д[авидович] Тамарченко, Издательский центр «Академия», 2012].

Teoriya literatury. Osnovnyye problemy $v$ istoricheskom osveshchenii. Obraz, metod, kharakter, red. G[rigoriy] L['vovich Abramovich] i dr., t. I-III, Izdatel'stvo AN SSSR, 1962-1965 [Теория литературы. Основные проблемы в историческом освещении. Образ, метод, характер, ред. Григорий Львович Абрамович и др., т. I-III, Издательство АН CCCP, 1962-1965].

Yakhina, Guzel'. Zuleykha otkryvayet glaza. AST, 2015 [Яхина, Гузель. Зулейха открывает глаза. АСТ, 2015].

\section{SYNKRETYZM GATUNKOWY POWIEŚCI WSPÓŁCZESNEJ (NA PODSTAWIE POWIEŚCI ZULEJKA OTWIERA OCZY GUZEL JACHINY)}

Streszczenie

W artykule na przykładzie powieści Zulejka otwiera oczy Guzel Jachiny ujawniane są cechy współczesnej powieści, a szczególnie synkretyzm gatunkowy, przejawiający się w hybrydyzacji formuł gatunkowych. Przedmiotem badań jest model powieściowy, w którym w ramach jednego utworu nastąpiło połączenie i przekształcenie formuł gatunkowych oraz różnych cech nowatorskich. W tekście przeanalizowane zostały kolejno przejawy synkretyzmu gatunkowego w powieści Jachiny: wykorzystanie wyznaczników powieściowych realizmu socjalistycznego i realizmu magicznego oraz intermedialność. Według autorki artykułu zastosowane zabiegi pozwalają na ukazanie wielopoziomowego konfliktu, który poszerza granice narracji.

Słowa kluczowe: kanon gatunkowy; transformacja gatunkowa; synkretyzm gatunkowy; model powieści historycznej; powieść-biografia; realizm magiczny; odrodzenie patriarchalnej zmitologizowanej świadomości; kinematografia literacka.

\section{THE GENRE SYNCRETISM OF THE MODERN NOVEL (NOVEL ZULEIKHA OPENS HER EYES BY GUZEL YAKHINA)}

\section{S u m m a ry}

This article uses the example of the novel Zuleikha opens her eyes by Guzel Yakhina to identify some features of the modern novel: genre syncretism, manifested in the hybridisation of genre formulas. The subject of the study is the model of a novel in which, within the framework of a single work, genre formulas and features of various traits of the novel are merged and transformed. The novel's genre syncretism manifests itself in the use of multi-level conflict, which contributes to the expansion of the boundaries of the narrative.

Keywords: genre canon; genre transformation; genre syncretism; model of historical novel; novel-biography; magic realism; rebirth of Patriarchal mythologised consciousness; literary cinematography. 